An appreciable reduction of spontaneous bleeding episodes was recorded during the administration of E.A.C.A.

No rise in antihaemophilic globulin (factor VIII) was demonstrated in any of the patients during E.A.C.A. therapy, nor were any significant changes observed in plasminogen and fibrinogen levels, or plasma $\alpha_{1}, \alpha_{2}, \beta$, or $\gamma$ globulins.

No abnormalities of marrow or liver function were detected during E.A.C.A. administration.

It is considered that the results warrant further large-scale study of E.A.C.A. at the clinical level in haemophilia, and the view is expressed that the drug or another fibrinolytic inhibitor -for example, the more potent aminoacid, aminomethyl cyclohexane carboxylic acid-may be of prophylactic value in the clinical management of high-grade haemophilia.

E.A.C.A. and placebo syrups were kindly provided by Dr. Hans Dahlström, of Kabi Pharmaceuticals. We are grateful to Dr. J. H. Wright for electrocardiography; to Dr. J. C. Eaton for liverfunction tests; and to Miss B. C. Bayley for technical help. The Medical Research Council provided financial support.

\section{BIBLIOGRAPHY}

Abe, T., Sato, A., Kazama, M., and Matsumura, T. (1962). Lancet, 2, 405 .

Ablondi, F. B., Hagan, J. J., Philips, M., and de Renzo, E. C. (1959). Arch. Biochem., 82, 153 .

Alkjaersig, N. (1960). In N.I.H. Conference on Thrombolytic Agents, edted by H. R. Roberts and D. Geraty, p. 316. Chapel Hill. - Fletcher, A. P., and Sherry, S. (1959). F. biol. Chem., 234, 832.
Andersson, L., and Nilsson, I. M. (1961). Acta chir. scand., 121, 291. and Olow, B. (1962). Thrombos. Diathes. haemorrh. (Stuttg.), 7, 391.

Astrup, T. (1956). Lancet, 2, 565.

Barkhan, P. (1964). Ibid., 2, 1061

Beck, E., Schmutzler, R., and Duckert, F. (1963). Thrombos. Diathes. haemorrh. (Stuttg.), 10, 106.

Bell, W. N., and Alton, H. G. (1954). Nature (Lond.), 174, 880.

Dubber, Anne H. C., McNicol, G. P., Douglas, A. S., and Melander, B. (1964). Lancet, 2, 1317.

Fletcher, A. P., Alkjaersig, N., and Sherry, S. (1962a). Amer. Y. Med., 33, 738 .

Gans,

Gans, H., and Krivit, W. (1962). Ann. Surg., 155, 268.

Grossi, C. E., Moreno, A. H., and Rousselot, L. M. (1961). Ibld., 153, 383.

Johnson, A. J., Skoza, L., and Claus, E. (1962). Thrombos. Diathes. haemorrh. (Stuttg.), 7, 203 (Abstract).

McNicol, G. P., and Douglas, A. S. (1964). Brit. med. Bull., 20, 233.

Fletcher, A. P., Alkjaersig, N., and Sherry, S. (1961a). \%. Urol. (Baltimore), 86, 829.

_ (Balimore, (1961b). F. Lab. clin. Med., 58, 34.

Z $=$ (1962). Ibid., 59, 15 .

- Gale, S. B., and Douglas, A. S. (1963). Brit. med. 7., 1, 909.

Melander, B., Gliniecki, E., Granstraud, B., and Hanshoff, G. (1964). Proceedings of Xth Congress of the International Society of Haematology, Stockholm, 30 August to 4 September.

Mikata, I., Hasegawa, M., Igarashi, T., Shirakura, N., Hoshida, M., and Toyama, K. (1959). Keio 7. Med., 8, 279.

Naeye, R. L. (1962). Blood, 19, 694.

Nolf, P. (1908). Arch. int. Physiol., 6, 306.

Ratnoff, O. D., and Menzie, C. (1951). 7. Lab. clin. Med., 37, 316.

Rausen, A. R., Cruchaud, A., McMillan, C. W., and Gitlin, D. (1961). Blood, 18, 710 .

Reid, W. O., Lucas, O. N., Francisco, J., Geisler, P. H., and Ensler, A. J. (1964). Amer. Ұ.' med. Sci., 248, 184.

Remmert, L. F., and Cohen, P. P. (1949). Y. biol. Chem., 181, 431.

Sherry, S., and Alkjaersig, N. (1957). Thrombos. Diathes. haemorrh. (Stuttg.), 1, 264.

Fletcher, A. P., and Alkjaersig, N. (1959). Physiol. Rev., 39, 343.

Steiger, B., White, J. G., and Krivit, W. (1962) 7. Lancet, 82, 421.

\title{
A Comparison of the Mortality from Bronchitis in Scotland and in England and Wales
}

\author{
EILEEN C. CROFTON,* B.M., B.CH.
}

Chronic bronchitis is an ill-defined disease which may not always have been accurately diagnosed as a cause of death. It is liable to be associated with other diseases of a chronic degenerative type, and the final diagnosis of cause of death may be a matter of individual choice and regional variation. The purpose of this inquiry was to ascertain to what extent there is a genuine difference in the mortality from chronic bronchitis in Scotland and in England and Wales, and to find, if any such difference exists, whether reasons could be given in explanation.

The death rates from bronchitis in Scotland and in England and Wales over the years 1940 to 1960 inclusive were standardized for age against a standard population, that of the combined population of Scotland and England and Wales obtained in the 1951 census. This procedure eliminates any bias due to a difference in age structure of the two populations. The results for males and females separately are shown in Fig. 1, A and B. According to these figures there is a marked preponderance of mortality in England and Wales compared with Scotland, which amounts to an average excess of $28.5 \%$ in the males and $23.6 \%$ in the females. In England and Wales, after the high values in 1940 and 1941, the death rate

\footnotetext{
- Honorary Research Assistant, Department of Respiratory Diseases and Tuberculosis, University of Edinburgh.
}

in males has been fairly steady apart from the sharp increase in 1951 associated with the influenza epidemic in the first two months of the year. Scotland, on the other hand, at its lower level, has shown a tendency for the rate to rise in the last six or seven years, the rate now approximating to that for England and Wales. The females show a steady decline in mortality over the 21-year period in both countries, but the decline has slowed down in Scotland in recent years.

\section{Death Rates Related to Degree of Urbanization}

The lower rates in Scotland might be due to the larger proportion of the population living under rural or semi-rural conditions. In fact the difference in urbanization between the two countries is not as great as might be expected, owing to the concentration of population in Scotland in the Forth-Clyde industrial belt. In Scotland in 1959, $45.8 \%$ of the population lived in small burghs (towns) or landward (rural) areas. In the same year in England and Wales the proportion was $40.6 \%$. $A$ priori it seems unlikely that a difference of $5.2 \%$ could entirely account for the large difference in the bronchitls mortality rates, but this possibility has been examined.

The mortality rates in the different parts of the two countries were compared, following the Registrar-Generals' 
classification into cities of over 100,000 inhabitants, large towns or burghs of 50,000 to 100,000 inhabitants, small towns or burghs of under 50,000 inhabitants, and rural or landward areas. The rates were standardized, using the 1951 census figures for the age distribution of the population of these areas. (The figures from the 1961 census were not yet available.)

The average of the standardized death rates between 1950 and 1953 are compared (Fig. 2, A and B). Fig. 2, A and B, also includes a comparison of Clydeside and Merseyside. Clydeside is the only conurbation in Scotland, and it is compared with Merseyside, the English conurbation most resembling it in climate. In each country there is a steady increase in bronchitis mortality corresponding to an increasing degree of urbanization, but in each case the rates for England and Wales are higher than for the corresponding areas in Scotland. In other words, though the degree of urbanization definitely affects the bronchitis mortality, it does not entirely account for the difference between the two countries. Further studies on atmospheric pollution may make it possible to determine the proportion of the population in each country exposed to the higher degrees of atmospheric pollution. In fact many areas classified as "rural" or "landward" might be sparsely populated areas situated to the windward of large, smoky, built-up

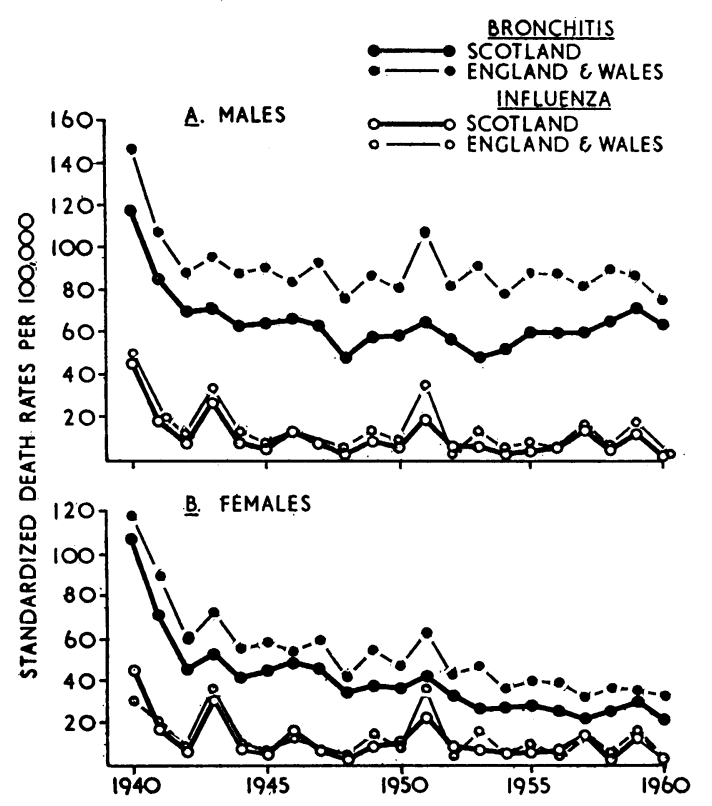

FIG. 1.-Bronchitis and influenza mortality: $A$ in males, and $B$ in females.

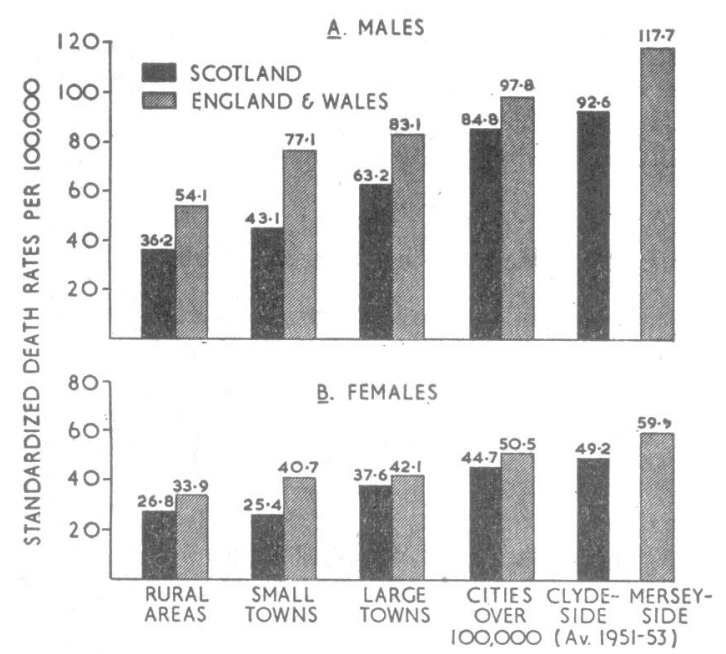

FIG. 2.-Average of standardized death rates from bronchitis from 1950-3 in urban and rural areas: A in males, and $B$ in females. areas, though our present classification is too crude to reveal this.

\section{Difference in Diagnostic Habit}

Another possibility is that the excess in England and Wales might not in fact be a genuine one, and might be due to a difference in the method of certifying the cause of death. The death certificate takes a different form in the two countries, and this could lead to a difference in the attribution of the cause of death.

\section{Other Respiratory Diseases}

If there is a difference in diagnostic habit in the two countries this may be indicated by examining other causes of death with which chronic bronchitis might be confused. Among respiratory diseases these would include pneumonia, respiratory tuberculosis, and carcinoma of the lung. If the standardized death rates from these four diseases are added together there still remains an excess of mortality in England and Wales, as is shown in Fig. 3, A and B. The temporary excess in Scotland among the females in the immediate post-war period is attributable to the high mortality at that time in young females from respiratory tuberculosis. It does not therefore appear that the excess of bronchitis mortality in England and Wales is due to under-diagnosis of other forms of respiratory disease.

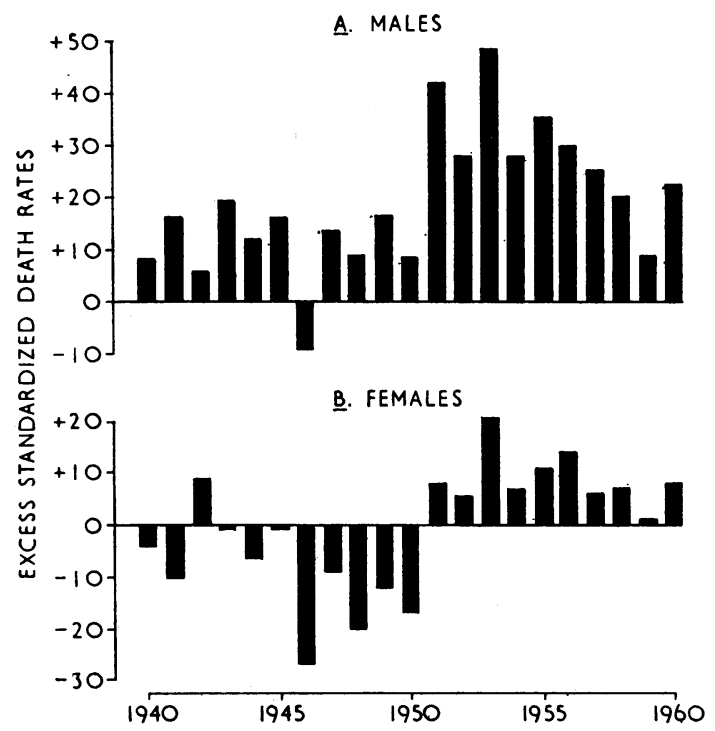

FIG. 3.-Excess mortality from the main respiratory diseases in England and Wales: $A$ in males, and $B$ in females. Each column represents the excess in England and $W$ ales over Scotland of the combined standardized death rates for bronchitis, pneumonia, pulmonary tuberculosis, and respiratory neoplasm.

\section{Myocardial Degeneration}

The diagnosis with which bronchitis is probably more likely to be confused is in fact not another respiratory disease but myocardial degeneration (93 $\mathrm{c}$ and $\mathrm{d}$ in the Fifth Revision of the International Statistical Classification of Diseases in use in 1940 to $1949 ; 422$ in the Sixth and Seventh Revisions in use between 1950 and 1960). If the standardized death rate from this disease is added to that for bronchitis the totals in both countries are roughly equal over the 21-year period (Fig. 4, A and B). In other words, the deficit in bronchitis in Scotland is balanced by the excess of deaths from myocardial degeneration. Indeed, in females over the whole period, and in males over the last seven years, the deficit in Scotland is more than balanced. Possibly bronchitis in Scotland was being under- 
diagnosed, and deaths attributed instead to myocardial degneration.

The simple comparison of standardized death rates could be misleading owing to the very high death rates in old people

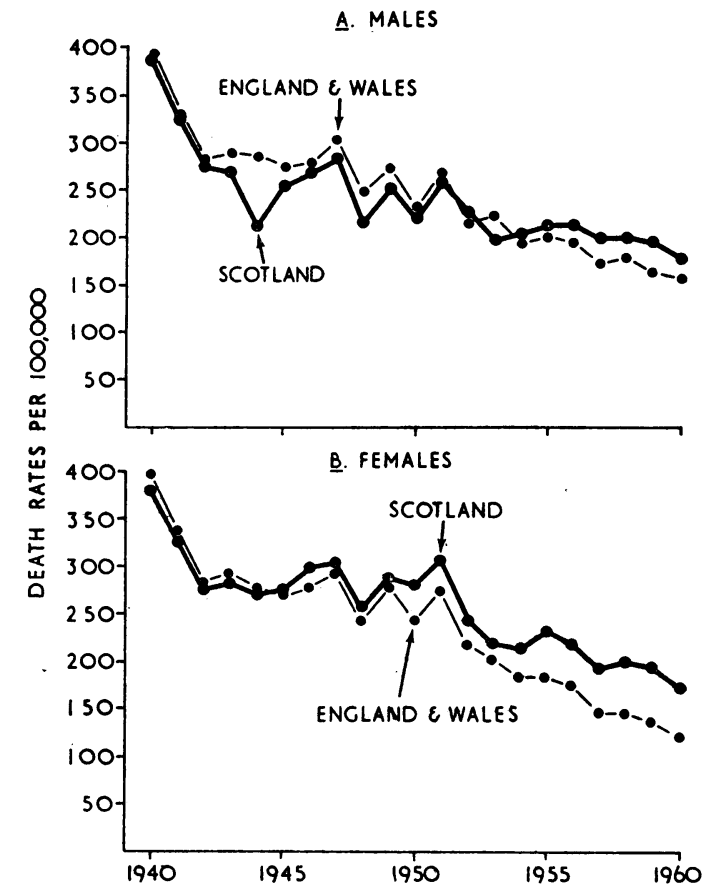

FIG. 4.-Sum of standardized death rates for bronchitis and myocardial degeneration: $A$ in males, and $B$ in females.

A. MALES AGED $45-54$

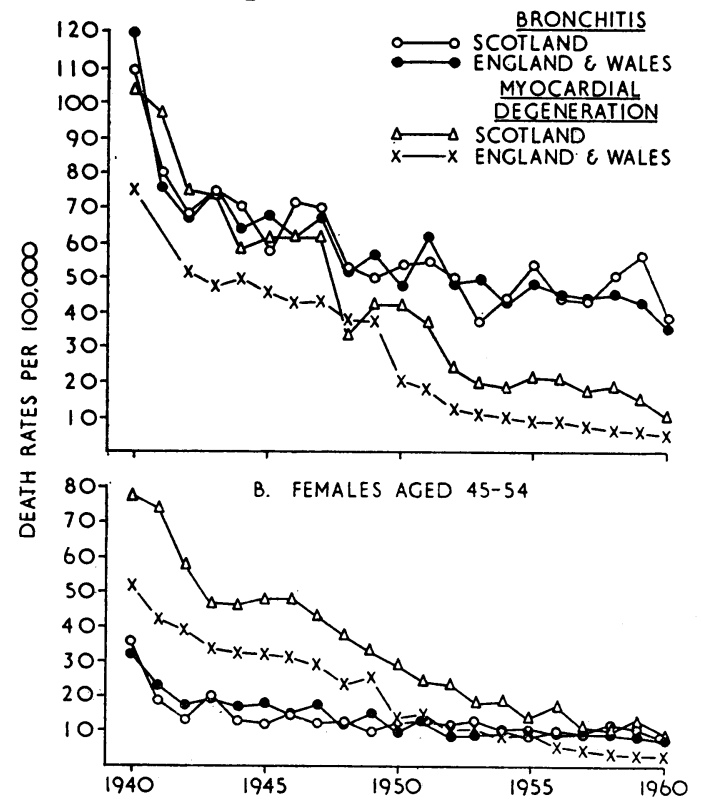

FIG. 5.-Age specific death rates for bronchitis and myocardial degeneration: $A$ in males aged $45-54$, and $B$ in females.

which can mask trends in younger age groups. A further analysis by 10-year age-specific death rates was accordingly made to elucidate this problem. The results are shown in Fig. 5, A and B, to Fig. 8, A and B, for the separate age groups 45 to 54,55 to 64,65 to 74 , and over 75 for males and females separately. ${ }^{1}$ The Table summarizes the data in Fig. 5, A and B,

1 The increased rate of fall in all age groups in 1950 is due to the introduction of the Sixth Revision of the International Statistical Classification of Diseases, a change which affected England and Wales more than Scotland. to Fig. 8, $\mathrm{A}$ and $\mathrm{B}$, and shows the average death rate from bronchitis and myocardial degeneration in the years 1940 to 1942 , the beginning of the period under consideration; in 1953 to 1955, when the apparent rise in male bronchitis in Scotland began ; and in 1958 to 1960 , the most recent years for which figures are available.

These findings suggest that similar factors are at work in Scotland and in England and Wales, resulting in a large decrease

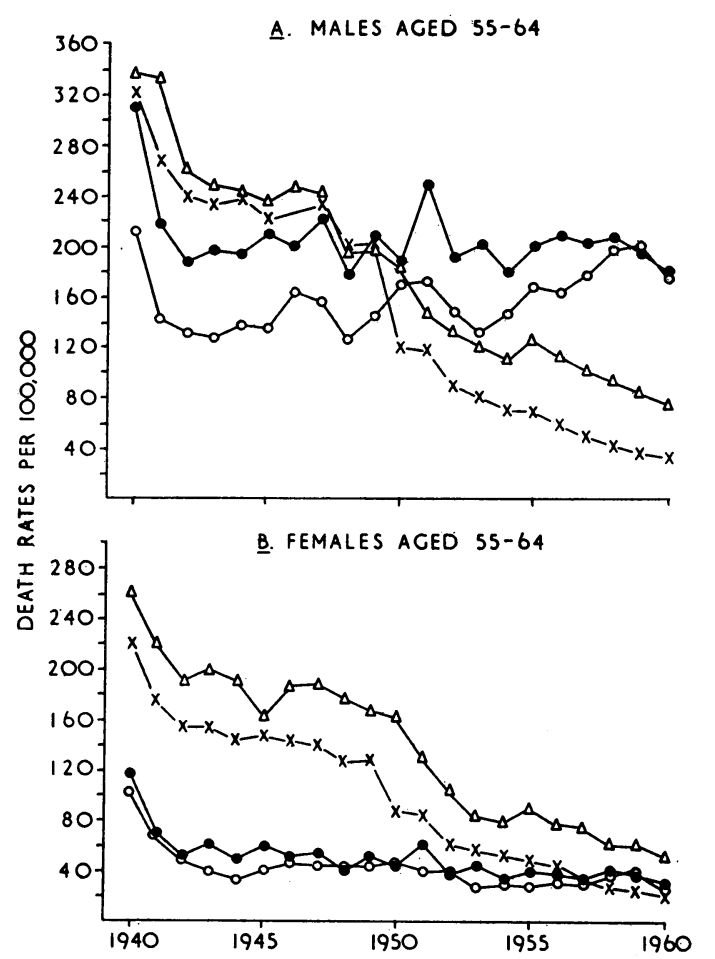

Fig. 6.-Age specific death rates for bronchitis and myocardial degeneration: $A$ in males aged $55-64$, and $B$ in
females.

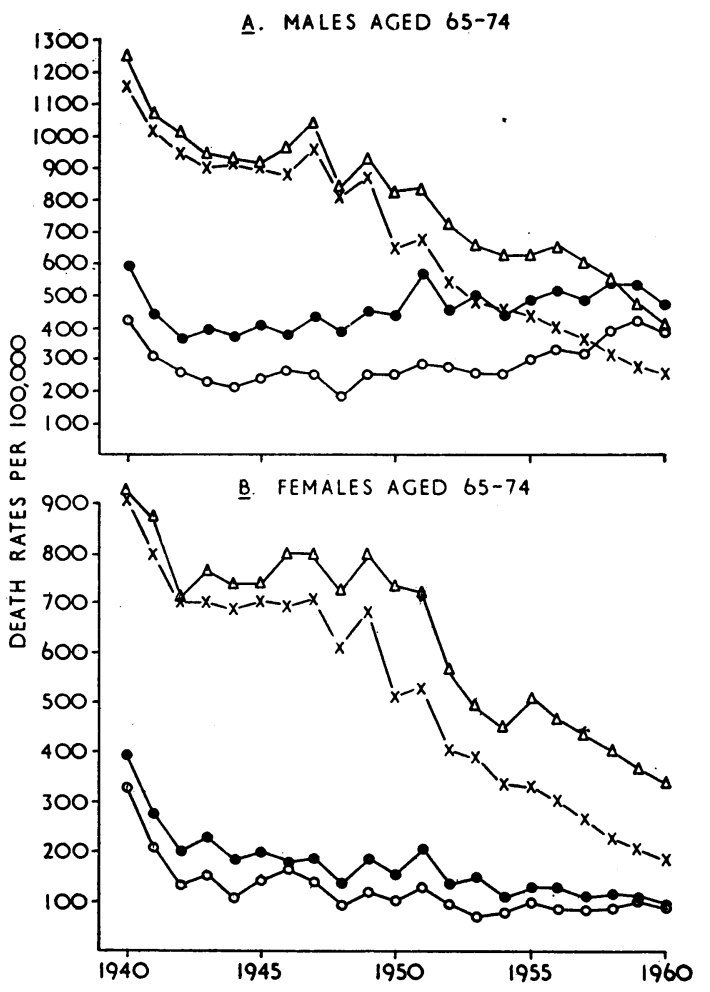

Fig. 7.-Age specific death rates for bronchitis and myocardial degeneration: $A$ in males aged $65-74$, and $B$ in 
of deaths attributed to myocardial degeneration at all ages. In both males and females in England and Wales, and in females in Scotland, this fall in myocardial degeneration is not offset by any rise in bronchitis mortality (with the exception of a rise which amounted to about $5 \%$ in males of 65 to 74 in England and Wales). In Scotland, on the other hand, the males aged 55 to 64 show a fall in myocardial degeneration almost exactly balanced by a rise in bronchitis mortality. In the other male age groups there is a rise in bronchitis mortality, though to a small degree compared with the fall in myocardial degeneration. Though it cannot therefore be completely excluded that some of the recent rise in male bronchitis mortality in Scotland is due to a redistribution of deaths formerly attributed to myocardial degeneration, it does not seem likely that this is the only factor.

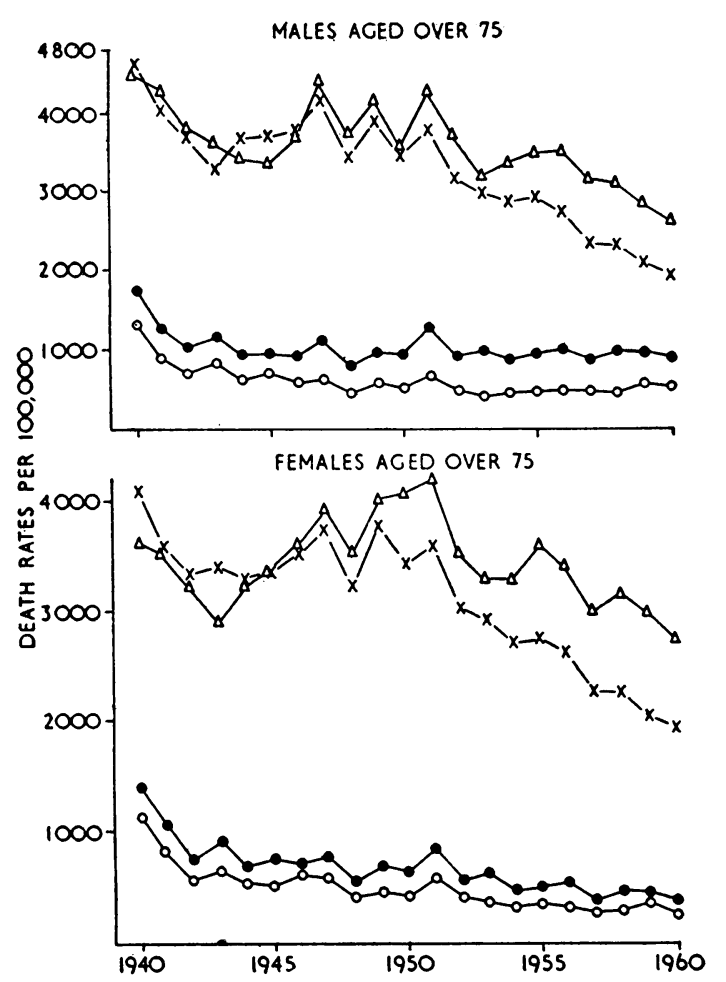

FIg. 8.-Age specific death rates for bronchitis and myocardial degeneration: $A$ in males aged over 75 , and $B$ in females.

Average Death Rates from Bronchitis and Myocardial Degeneration During Three Periods

\begin{tabular}{|c|c|c|c|c|c|c|}
\hline \multirow{3}{*}{\multicolumn{3}{|c|}{ Age and Sex Category }} & \multicolumn{4}{|c|}{ Changes in Death Rate per 100,000} \\
\hline & & & \multicolumn{2}{|c|}{$\begin{array}{l}\text { Between } \\
1940-2 \text { and 1958-60 } \\
\end{array}$} & \multicolumn{2}{|c|}{$\begin{array}{l}\text { Between } \\
1953-5 \text { and } 1958-60\end{array}$} \\
\hline & & & Bronchitis & $\begin{array}{c}\text { Myocardial } \\
\text { Degeneration }\end{array}$ & Bronchitis & $\begin{array}{c}\text { Myocardial } \\
\text { Degeneration }\end{array}$ \\
\hline $\begin{array}{c}\text { Scotland, maler } \\
45-54 \\
55-64 \\
65-74 \\
\text { Over } 75 \\
\end{array}$ & $\begin{array}{l}. \\
\cdots \\
\cdots \\
\cdots\end{array}$ & $\begin{array}{l}\cdots \\
\cdots \\
\cdots \\
\end{array}$ & $\begin{array}{r}-38 \\
+27 \\
+65 \\
-441 \\
\end{array}$ & $\begin{array}{r}-76 \\
-26 \\
-642 \\
-1,292 \\
\end{array}$ & $\begin{array}{r}+2 \\
+39 \\
+135 \\
+96 \\
\end{array}$ & $\begin{array}{r}-5 \\
-37 \\
-155 \\
-450 \\
\end{array}$ \\
\hline $\begin{array}{c}\text { England and } W \\
45-54 \\
55-64 \\
65-74 \\
\text { Over } 75 \\
\end{array}$ & $\begin{array}{l}\text { Vales, } \\
\cdots \\
\because \\
\cdots \\
\end{array}$ & $\begin{array}{c}\text { ales } \\
\because \\
\because \\
\cdots \\
\end{array}$ & $\begin{array}{r}-47 \\
-40 \\
+33 \\
-390 \\
\end{array}$ & $\begin{array}{r}-58 \\
-238 \\
-759 \\
-2,001 \\
\end{array}$ & $\begin{array}{r}-6 \\
+1 \\
+24 \\
+3 \\
\end{array}$ & $\begin{array}{r}-5 \\
-36 \\
-182 \\
-819 \\
\end{array}$ \\
\hline $\begin{array}{c}\text { Scotland, fema } \\
45-54 \\
55-64 \\
65-74 \\
\text { Over } 75 \\
\end{array}$ & $\begin{array}{r}\text { ales } \\
\ldots \\
\ldots \\
\ldots \\
.\end{array}$ & $\begin{array}{l}\cdots \\
\cdots \\
\cdots \\
\end{array}$ & $\begin{array}{r}-13 \\
-40 \\
-123 \\
-561 \\
\end{array}$ & $\begin{array}{r}-58 \\
-165 \\
-469 \\
-169 \\
\end{array}$ & $\begin{array}{r}0 \\
+4 \\
+13 \\
-42 \\
\end{array}$ & $\begin{array}{r}-6 \\
-26 \\
-114 \\
-439 \\
\end{array}$ \\
\hline $\begin{array}{l}\text { England and } \\
\text { females } \\
45-54 \\
55-64 \\
65-74 \\
\text { Over } 75\end{array}$ & $\begin{array}{c}\text { Wales, } \\
\ldots \\
\ldots \\
\ldots \\
.\end{array}$ & $\begin{array}{l}\cdots \\
\cdots \\
\cdots\end{array}$ & $\begin{array}{r}-15 \\
-46 \\
-178 \\
-695\end{array}$ & $\begin{array}{r}-40 \\
-154 \\
-501 \\
-1,589\end{array}$ & $\begin{array}{r}-1 \\
-3 \\
-24 \\
-132\end{array}$ & $\begin{array}{r}-5 \\
-21 \\
-43 \\
-718\end{array}$ \\
\hline
\end{tabular}

Further evidence could be obtained by a comparison of the differences in mortality rates for myocardial degeneration in urban and rural areas. Bronchitis mortality rates (Fig. 2, A and B) show a clear gradation, the highest levels being obtained in the most densely populated areas, and the lowest in the rural areas. In other words, there is a definite urban-rural gradient. Fig. 9 shows the average age-specific mortality rate for chronic degenerative disease of the heart between 1951 and $1960,^{2}$ in the Registrar-Generals' five classifications of area. These figures show that only in Scotland among males aged 45 to 64 is there an urban-rural gradient for chronic degenerative disease of the heart. This lends support to the possibility that this group contains some cryptic bronchitis.

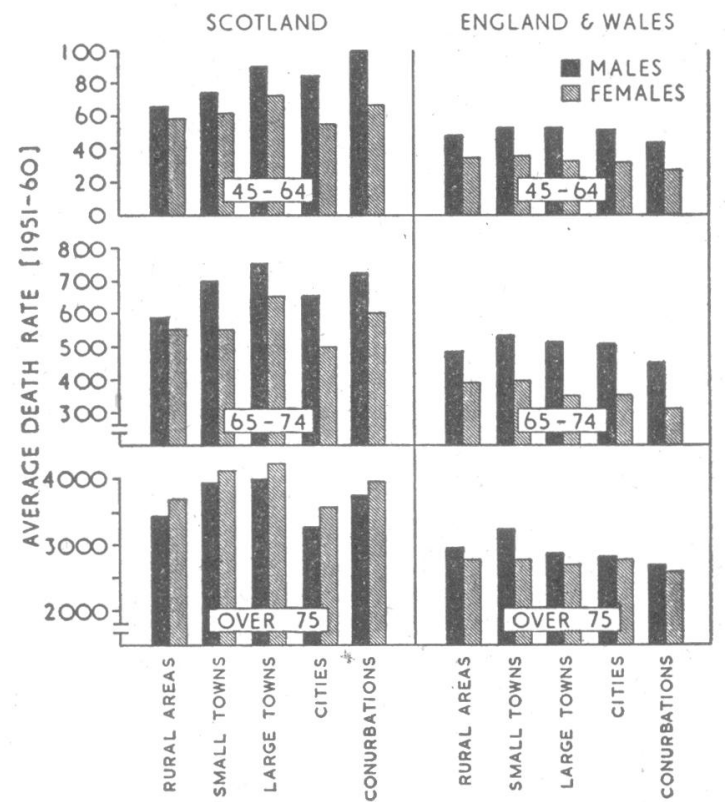

FIG. 9.-Comparison of death rates from chronic degenerative disease of the heart in urban and rural areas in males and females.

\section{Primary and Secondary Causes of Death}

The Report of the Registrar-General for Scotland (1958) compared the primary and secondary causes of death in the year 1956. Of 8,665 cases of death from myocardial degeneration, 389 cases have bronchitis listed as a secondary cause of death. If this number is added to the number of bronchitis deaths in that year the crude bronchitis death rate becomes 47.9 per 100,000 , or an increase of $18.7 \%$ over the recorded bronchitis death rate. Similarly bronchitis is listed as a secondary cause of death in 710 cases of heart disease (International Statistical Classification of Diseases 410-416, 420, 421, 422, $430-434,440-443)$. If these were all ascribed to bronchitis the bronchitis death rate would rise to 54.2 per 100,000 , an increase of $34.2 \%$. In all, 1,178 cases dying from any cause have bronchitis listed as a secondary cause, and if these are ascribed to bronchitis the death rate becomes 63.3 per 100,000 , an increase of $56.7 \%$.

Though no completely comparable analysis has been done for England and Wales, there has been an analysis of "complicating" and "contributory" causes of death in a $10 \%$ sample of deaths selected from the first six months of 1951 (Registrar-

- Chronic degenerative disease of the heart includes 421 and 422 in the International Statistical Classification of Diseases. The figures contributed by 421 (chronic endocarditis not specified as rheumatic) are relatively small and do not seriously affect the comparison with 422 alone, figures for which are not available by areas. The calculaton of mortality rates was based on figures obtained in the 1951 census, but the results do not differ significantly from rates calculated census, but the results do not differ significantly from rates calculated
by applying the 1951 sex and age distribution to the totals of the 1961 census. 
General, 1951). It has been assumed that "complicating" and "contributory" correspond to the term "secondary" used in the reports of the Registrar-General for Scotland. The results are shown in Fig. 10. There is little difference in the percentage increase in the two countries when the primary cause of death is myocardial degeneration or heart disease, but the addition of all cases dying of any cause in which bronchitis is listed as a complicating or contributory cause of death results in a much larger percentage increase in the bronchitis death rate in England and Wales than it does in Scotland-78.8\% compared with $56.7 \%$. Unfortunately for the sample selected the six months January to June normally include a higher proportion of bronchitis deaths than the six months July to December, and in this particular year there was a large-scale influenza epidemic which may further have distorted the figures. A second analysis of a $10 \%$ sample was carried out by the World Health Organization Centre for Classification of Diseases (unpublished data) in July to December 1958, a season when bronchitis death rates tend to be lower, and a year in which the bronchitis death rate was not abnormal. Here the percentage increase in the crude bronchitis death rate when augmented by all cases in which bronchitis was mentioned as a complicating or contributory cause was $69.7 \%$, a figure considerably in excess of the Scottish figure for 1956 based on all deaths for the whole year. These figures suggest that there is a genuine difference in overall bronchitis mortality in the two countries, which cannot be explained by differences in diagnostic habit.

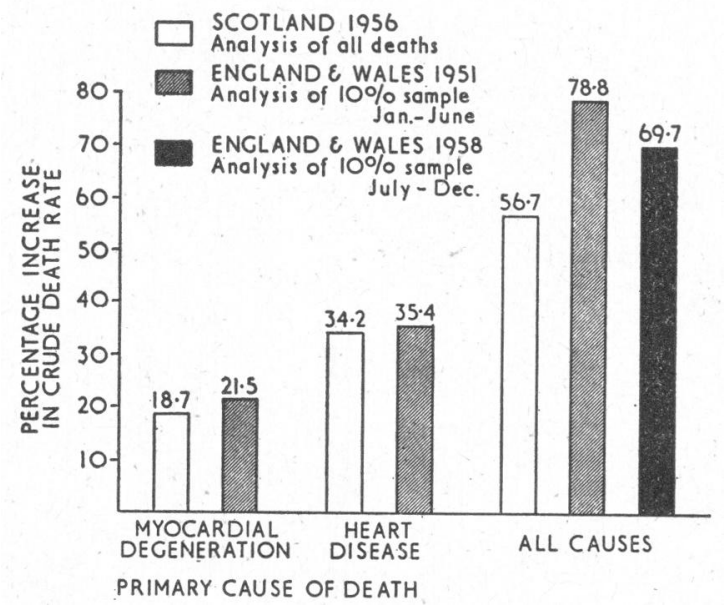

FIG. 10.-Proportional increase in bronchitis death rate in Scotland and England and Wales produced by including bronchitis certified as secondary cause of death.

\section{Effects of Smoking}

The lower rate of bronchitis mortality in Scotland compared to England and Wales may be partly due to a delayed effect of cigarette smoking, if the smoking habit had spread more slowly in Scotland than in England and Wales and was only recently showing its full effect. If this is so it would account for the rising rate in bronchitis mortality in Scotland in men of 45 to 64 . This question has been more fully discussed elsewhere (Crofton and Crofton, 1963), where a comparison of the changes in the male-female ratios. of the death rates at different ages in persons born at different times supports the suggestion of a later smoking effect in Scotland than in England and Wales.

\section{Summary}

A comparison of the bronchitis mortality rates in Scotland and in England and Wales for the years 1940 to 1960 shows that there is a considerable excess in England and Wales, but that there has been a recent rise in males in Scotland, particularly in the younger age groups. The excess in England and Wales is seen in every type of urban and rural area, and is not due to a lower proportion of the total population living under rural conditions.

There does not appear to be any significant difference in the diagnosis of other forms of respiratory disease in the two countries, but a comparison of mortality rates from myocardial degeneration suggests that some of the recent rise in Scottish males could be due to a re-allocation of deaths formerly certified as myocardial degeneration, though reasons have been given which indicate that this is not the only factor.

An analysis based on the Report of the Registrar-General for Scotland in 1956 listing secondary causes of death shows that, even if every death where bronchitis is listed as a secondary cause were attributed to bronchitis, the enhanced death rate from bronchitis is still below the level reached in England and Wales. Analyses in England and Wales show that there is an amount of "complicating" and "contributory" bronchitis which is similar to that found in Scotland. Though the difference of bronchitis mortality rates between the two countries may not be as large as at first sight appears, it remains true that Scotland has a lower rate at the present time than England and Wales. The evidence suggests that the degree of difference is becoming less, particularly in the younger males. This may be due to the cigarette-smoking habit having spread more slowly in Scotland. Cigarette smoking may have begun to show its major effect on mortality only in the last few years.

Thanks are due to Professor Donald Reid, of the London School of Hygiene and Tropical Medicine, for his encouragement and constructive criticism, and to Mr. Stanley Sklaroff and Dr. E. A. Smith, of the Department of Public Health, University of Edinburgh, for useful suggestions. The World Health Organization Centre for Classification of Disease in the General Register Office in London has been most helpful in providing unpublished material. Mrs. Joan Valentine has given valuable help with the statistics and clerical work, and the Royal Victoria Hospital Tuberculosis Trust has provided funds for carrying out part of the investigation.

\section{REFERENCES}

Crofton, E., and Crofton, J. (1963). Brit. med. f., 2, 1161 .
Registrar-General's Statistical Review of England and Wales for the Year 1951, Part III Text, medical. H.M.S.O., London.

Report of the Registrar-General for Scotland. (1958). Appendix XII. H.M.S.O., London.

World Health Organization Centre for Classification of Disease. (Un- 